\title{
How useful are our present statistics on sexually- transmitted diseases?
}

\author{
KEVIN WOODCOCK \\ Southampton Special Treatment Centre, Bullar Street, Southampton SO2 0NH
}

In order to preserve patient anonymity venereal infections are not notifiable as such, but, since the establishment of 'special clinics' as a result of the 'Venereal Diseases Act, 1916', these clinics have provided annual reports of the number of cases treated. It is impossible to know, in retrospect, how complete a picture of the incidence of venereal diseases was provided by these statistics during the inter-war years, but by 1950 two changes had occurred which had a dramatic effect on the figures. The first was the discovery that penicillin provided a rapid and effective cure for both gonorrhoea and syphilis and the second was the introduction of the National Health Service in 1948. General practitioners also had penicillin at their disposal, and the free treatment of venereal disease no longer depended on attendance at the 'special clinics' which were, and still are, the only source of venereal disease statistics. Furthermore, the ability to cure gonorrhoea rapidly had led to the possibility of a few patients repeatedly becoming re-infected and so distorting the 'new cases' figures. In 1951 the clinics first reported the number of cases of 'non-gonococcal urethritis' diagnosed; these figures are even more complicated by the additional problem of deciding whether a late recurrence of symptoms represents a re-infection, or a relapse of the condition previously considered cured. Also, the desire for more information about patients attending the clinics with 'other conditions' led to the addition, in 1971, of seven more categories to the list of diseases to be specifically reported; thus the increased possibility of multiple diagnoses and of variations in diagnostic criteria, as well as the problem of distinguishing relapses from re-infections, has added further to the complexity of interpreting the statistics.

\section{Previous work}

Unfortunately information on cases treated outside the clinics is scanty: on the basis of a 35 per cent.

Received for publication October 11, 1974

Paper presented at a meeting of the MSSVD on April 26, 1974. Previously unpublished data used in this paper are taken from a report on V.D. statistics presented by the author for the M.Sc. Social Medicine examination, University of London, 1973. response to a postal survey it was concluded that gonorrhoea must be under-reported by at least 15 per cent. and syphilis by 25 per cent. (British Cooperative Clinical Group, 1959); a similar survey in East Scotland produced an 85 per cent. response and indicated a 10 to 12 per cent. under-reporting of gonorrhoea (British Co-operative Clinical Group, 1968); more recently, but on what evidence is not stated, it has been suggested that all the figures may be 25 per cent. too low (Wigfield, 1971); in $\mathrm{N}$. Humberside it was calculated that the proportion of cases treated outside the clinics was unlikely to have exceeded 20 per cent., even allowing for a possible 25 per cent. under-recording by the G.Ps surveyed (Heywood and Bacon, 1973). The 'Study of Morbidity Statistics in General Practice' found that gonorrhoea and venereal disease other than syphilis accounted for 2 per cent. of consultations, and 1 per cent. of patients consulting (Logan and Cushion, 1958); from $N$. Wales comes the information that, of 508 consecutive patients, 0.8 per cent. had male genital problems and 8.4 per cent. gynaecological problems (Bebbington, 1969); from Scotland that 11 years' practice with nearly 1,000 patients aged 15 to 44 produced four cases of gonorrhoea (McGregor, 1969); from the R.A.F. that 8,018 consultations led to 288 referrals to hospital of which 2.1 per cent. were for V.D. (Beeton, 1969); and at the Belfast Venereal Disease Clinic it was found that, of patients with symptoms, 50 per cent. had consulted their family doctor before attending the clinic (Mahoney, 1972); but nowhere can be found data, comparable with the clinic figures, about the number of cases diagnosed, treated, and not referred to a clinic.

There is no published information about possible variations in laboratory techniques and standards over time and between places, nor any information on possible variations of criteria for diagnosing 'new cases', relapses, or re-infections. There is, however, some evidence that the statistics can be confusing: a study in Belfast reported that in 25 per cent. of both male and female patients attending the Venereal Disease clinic no disease was found, and that 1,753 patients contributed 2,093 diagnoses (Pemberton, 
McCann, Mahoney, Mackenzie, Dougan, and Hay, 1972). Similarly, in Aberdeen, 1,603 female patients contributed 2,093 diagnoses, of which 1,052 were non-venereal, and 265 were infants with no abnormality being checked for congenital venereal disease before adoption (Thompson and Rutherford, 1972). Yet two recent publications have contained graphs entitled 'New patients attending clinics in England and Wales' whilst using figures for total diagnoses made-which include not only multiple diagnoses on the same patients but also diagnoses of 'no abnormality' (Catterall and Morton, 1970; Catterall, 1973).

\section{Objectives}

The objectives of this paper are:

(1) To enumerate, with specific examples, some of the ways in which the present STD statistics are deficient;

(2) To suggest practical ways in which adjustments may make the statistics more useful.

DEFECTS

(i) Data are available from no source other than STD clinics. Table I shows the results of a survey of a Gynaecology outpatient department and a General Practice in S. Kensington aimed at discovering what proportion of patients attending had histories suggesting the possibility of a sexually-transmitted disease (mainly vaginal or urethral discharge or a history of contact with a known case). Although the numbers were small, if this situation were reflected in every Gynaecology clinic and General Practice in the country, the total numbers involved would completely eclipse the STD clinic figures.

(ii) 'Cases' are not 'spells of infection' nor 'persons infected' but only diagnoses made. A sample of records of patients attending the St. Mary's Hospital Special Clinic during 1971 were examined to discover what contribution these patients had made to the annual case statistics. The sample consisted of all female patients and alternate male patients attending the clinic on days chosen from a random number table to fill a sample frame stratified to include one day from each week, from each quarter of the year. From the results, shown in Table II, it can be seen that there were 80 per cent. more 'cases' than persons; that nevertheless, 55 per cent. of the patients contributed only a single 'case'; but that 8 per cent. of the patients had four or more diagnoses made and contributed 22 per cent. of the total 'cases'.

(iii) A different aspect is demonstrated in Table III : gonorrhoea was diagnosed 2.5 times more often in male patients than in female patients, which might be considered useful information for policy decisions of one kind or another. However, homosexual males accounted for 13.9 cases per 100 , while ten females per 100 were treated as contacts of gonorrhoea without waiting for a diagnosis to be made. Hence treatment for gonorrhoea was given only $1 \cdot 1$ times more often to heterosexual males than to females, which fact, undetectable from the routine statistics, might lead to different decisions.

TABLE I A comparison between Gynaecology, General Practice, and Venereology departments of new $S T D$ presentations as a percentage of total attendances and as an estimated number seen per week

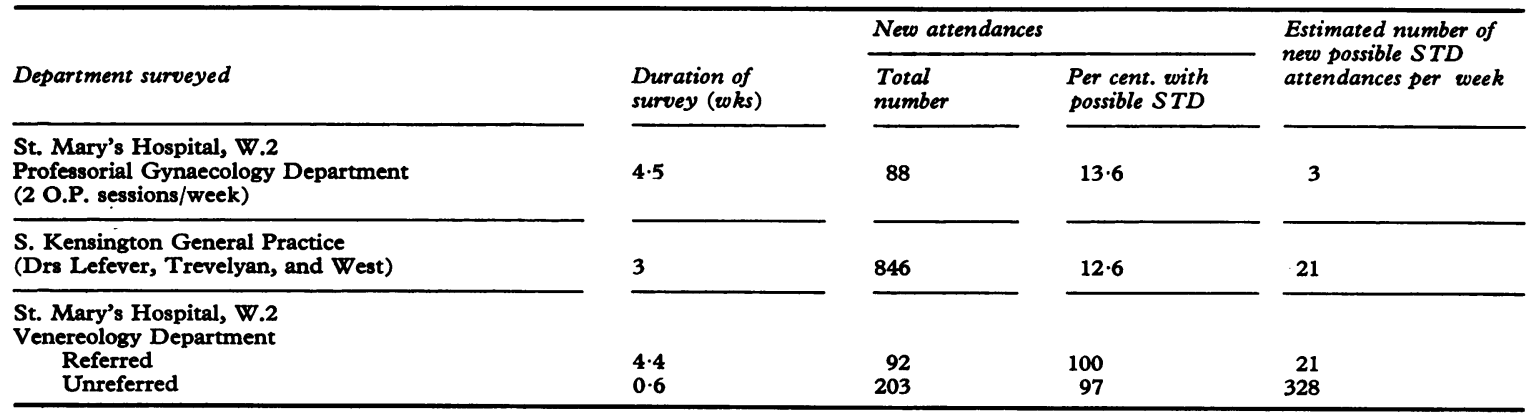

TABLE II Number of patients providing the specified number of cases during 1971, by sex

\begin{tabular}{|c|c|c|c|c|c|c|c|c|c|}
\hline \multirow[b]{2}{*}{ Sex } & \multicolumn{7}{|c|}{ Total number of cases contributed } & \multirow{2}{*}{ Total persons } & \multirow{2}{*}{ Total cases } \\
\hline & 1 & 2 & 3 & 4 & 5 & 6 & 7 & & \\
\hline $\begin{array}{l}\text { Male } \\
\text { Female }\end{array}$ & $\begin{array}{l}307 \\
286\end{array}$ & $\begin{array}{l}134 \\
131\end{array}$ & $\begin{array}{l}68 \\
57\end{array}$ & $\begin{array}{l}31 \\
17\end{array}$ & $\begin{array}{l}13 \\
11\end{array}$ & $\begin{array}{l}3 \\
6\end{array}$ & $\begin{array}{l}5 \\
2\end{array}$ & $\begin{array}{l}561 \\
510\end{array}$ & $\begin{array}{r}1,017 \\
892\end{array}$ \\
\hline Both & 593 & 265 & 125 & 48 & 24 & 9 & 7 & 1,071 & 1,909 \\
\hline
\end{tabular}


TABLE III Effect on male/female gonorrhoea ratio of excluding homosexual cases and including cases treated 'epidemiologically'

\begin{tabular}{|c|c|c|c|}
\hline \multirow[b]{2}{*}{$\operatorname{Sex}$} & \multicolumn{3}{|c|}{ Column } \\
\hline & 1 & 2 & 3 \\
\hline $\begin{array}{l}\text { Male } \\
\text { Female }\end{array}$ & $\begin{array}{l}45 \cdot 8 \\
18 \cdot 6\end{array}$ & $\begin{array}{l}31.9 \\
18.6\end{array}$ & $\begin{array}{l}31.9 \\
28.6\end{array}$ \\
\hline $\mathbf{M} / \mathbf{F}$ ratio & $2 \cdot 5$ & $1 \cdot 7$ & $1 \cdot 1$ \\
\hline
\end{tabular}

Column (1) Gonorrhoea cases diagnosed per 100 persons in sample

(2) As 1 , but excluding homosexually acquired infections

(3) As 2 , but including cases treated for gonorrhoea because of history, without waiting for a diagnosis to be made

(iv) No information is available about the site or severity of infection. The distribution of anal and urethral infections amongst 121 homosexual patients statistics, but some indication of whether an organism was isolated from purulent urethral discharge, an inflamed throat, the bloodstream of a patient with septicaemia, or an apparently healthy cervix, would clearly be desirable. in the case records survey is shown in Table IV. This format is too complex for routinely published (v) The available information does not relate to local populations. By going through the case registers for 1971 of nine clinics in and around $W$. London and by recording information about all patients with gonorrhoea giving an address in W.2 or W.9 an attempt was made to relate information about gonorrhoea to the 1971 Census Data on residents in W.2 and W.9. The result is shown in the Figure; in epidemiological language this should represent the age/sex specific incidence (spells). The obvious next step would be to compare this information with similar information from elsewhere, but none is available. Even the national figures, shown in Table V, cannot be used directly: not only are the age groupings used rather irregular, but for ages under 16 and over 25 the case figures have been related to total populations-which include both babies and octogenarians. Recalculating the figures as shown in Table VI allowed some comparison to be made; it can be seen that the incidence in W.2 and W.9 appears to be five to fifteen

TABLE IV Homosexual males' case histories analysed to demonstrate the distribution of proctitis and urethritis episodes during 1971

No. of persons experiencing this number of episodes of proctitis

\begin{tabular}{l}
\hline 0 \\
1 \\
2 \\
3 \\
$4+$ \\
\hline
\end{tabular}

Total persons

\begin{tabular}{|c|c|c|c|c|}
\hline 0 & 1 & 2 & 3 & $4+$ \\
\hline $\begin{array}{r}28 \\
26 \\
9 \\
2\end{array}$ & $\begin{array}{r}20 \\
8 \\
2 \\
2 \\
1(5)\end{array}$ & $\begin{array}{r}12 \\
3 \\
1\end{array}$ & $\begin{array}{l}3 \\
3\end{array}$ & 1 \\
\hline 65 & 33 & 16 & 6 & 1 \\
\hline
\end{tabular}

Total persons

$\begin{array}{r}64 \\ 40 \\ 12 \\ 4 \\ 1 \\ \hline\end{array}$

121

TABLE V 1971. Incidence of new cases of gonorrhoea seen at hospital clinics in England, as published by the D.H.S.S.

\begin{tabular}{|c|c|c|c|c|c|c|}
\hline \multirow{2}{*}{$\operatorname{Sex}$} & \multicolumn{5}{|c|}{ Incidence per 100,000 population aged } & \multirow{2}{*}{ All ages } \\
\hline & Under 16 & 16 and 17 & 18 and 19 & $20-24$ & $25+$ & \\
\hline $\begin{array}{l}\text { Male } \\
\text { Female }\end{array}$ & $\begin{array}{l}2 \cdot 15 \\
7 \cdot 03\end{array}$ & $\begin{array}{l}161 \cdot 37 \\
348 \cdot 62\end{array}$ & $\begin{array}{l}523.9 \\
558 \cdot 8\end{array}$ & $\begin{array}{l}683 \cdot 29 \\
370 \cdot 08\end{array}$ & $\begin{array}{r}159 \cdot 26 \\
36 \cdot 58\end{array}$ & $\begin{array}{c}169 \cdot 26 \\
75 \cdot 9\end{array}$ \\
\hline Total & 4.53 & $252 \cdot 47$ & 541.06 & $527 \cdot 46$ & $94 \cdot 30$ & $121 \cdot 26$ \\
\hline
\end{tabular}

TABLE VI 1971. Incidence of new cases of gonorrhoea reported from clinics in England and Wales, compared with that calculated for London postal districts W.2 and W.9

\begin{tabular}{|c|c|c|c|c|c|c|}
\hline \multirow[b]{2}{*}{ Area } & \multirow[b]{2}{*}{$\operatorname{Sex}$} & \multicolumn{5}{|c|}{ Incidence of cases of gonorrhoea in persons aged: } \\
\hline & & $\begin{array}{l}<20 \text { per } 1,000 \\
\text { pop. aged 15-19 }\end{array}$ & $\begin{array}{l}20-24 \text { per } 1,000 \\
\text { pop. aged } 20-24\end{array}$ & $\begin{array}{l}25+\text { per } 1,000 \\
\text { pop. aged } 25-44\end{array}$ & $\begin{array}{l}\text { All ages per } 1,000 \\
\text { pop. aged } 15-44\end{array}$ & $\begin{array}{l}\text { All ages per } 1,000 \\
\text { total population }\end{array}$ \\
\hline \multirow[t]{2}{*}{ England and Wales } & $\begin{array}{l}\text { Male } \\
\text { Female }\end{array}$ & $\begin{array}{l}2 \cdot 8 \\
3 \cdot 8\end{array}$ & $\begin{array}{l}6 \cdot 7 \\
3 \cdot 6\end{array}$ & $\begin{array}{l}3 \cdot 7 \\
1\end{array}$ & $\begin{array}{l}4 \cdot 1 \\
2\end{array}$ & $\begin{array}{l}1 \cdot 6 \\
0 \cdot 7\end{array}$ \\
\hline & Total & $3 \cdot 3$ & $5 \cdot 2$ & $2 \cdot 3$ & 3 & $1 \cdot 2$ \\
\hline \multirow{2}{*}{$\begin{array}{l}\text { London } W .2 \text { and } \\
W .9\end{array}$} & $\begin{array}{l}\text { Male } \\
\text { Female }\end{array}$ & $\begin{array}{l}21 \cdot 6 \\
20 \cdot 3\end{array}$ & $\begin{array}{l}68 \cdot 5 \\
18 \cdot 6\end{array}$ & $\begin{array}{r}51 \cdot 5 \\
7 \cdot 7\end{array}$ & $\begin{array}{l}51 \cdot 6 \\
12 \cdot 5\end{array}$ & $\begin{array}{r}25 \cdot 3 \\
5 \cdot 6\end{array}$ \\
\hline & Total & 21 & $40 \cdot 7$ & $31 \cdot 2$ & $32 \cdot 3$ & $15 \cdot 2$ \\
\hline
\end{tabular}




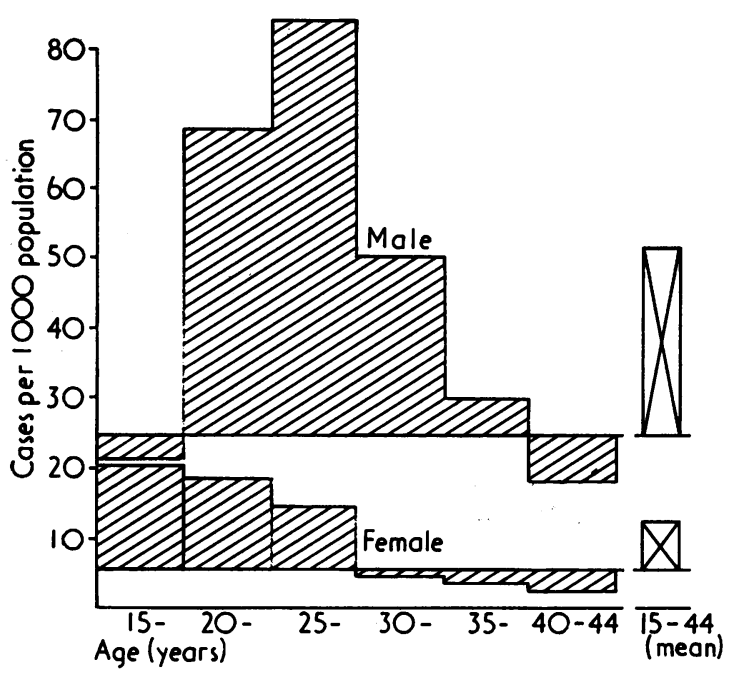

F IGURE 1971. Gonorrhoea cases in $W .2$ and $W .9$ per 1,000 population, by age and sex.

The histogram baseline for male and female cases is the incidence calculated as total cases per totai population, by sex, of all ages

times that of the country as a whole, which might have been of interest were it not for the fact that addresses are recorded primarily to ensure that the patient can be contacted. Some patients do not want to be contacted and give a false address; some give the address of a friend; some a business address; some the hotel in which they are staying; and some may have forgotten to mention that they have moved since their address was first recorded. Table VII shows the results of a small survey to discover how reliable the recorded postal district was.

TABLE VII Extent of agreement between postal districts of patients as shown in case register and as reported by patients to consulting doctor

\begin{tabular}{|c|c|c|c|c|}
\hline \multirow{2}{*}{ Patients } & \multirow{2}{*}{$\begin{array}{l}\text { Agreement } \\
\text { (Per cent.) }\end{array}$} & \multirow{2}{*}{$\begin{array}{l}\text { Disagreement } \\
\text { (Per cent.) }\end{array}$} & \multicolumn{2}{|c|}{ Total patients } \\
\hline & & & No. & Per cent. \\
\hline $\begin{array}{l}\text { New patients } \\
\text { Re-attenders }\end{array}$ & $\begin{array}{l}99 \\
57\end{array}$ & $\begin{array}{r}1 \\
43\end{array}$ & $\begin{array}{r}79 \\
110\end{array}$ & $\begin{array}{l}100 \\
100\end{array}$ \\
\hline Total & 75 & 25 & 189 & 100 \\
\hline
\end{tabular}

Thus not only is the information being collected and published incomplete by an unknown amount, and inadequate because it tells only of laboratory diagnoses and nothing about people or their problems, it is also unusable at a local level because it relates to no identifiable population. Any apparent trends shown might be due to variations in laboratory techniques or in diagnostic criteria, to more or less people going to STD clinics instead of other medical agencies, to large differences in the sexual behaviour of a few people, to small differences in the sexual behaviour of many people, or to variations in the population 'at risk', produced, for example, by the tourist industry.

\section{SUGGESTIONS}

(i) The first requirement is the establishment of a working party to decide for what purposes the statistics are required and to endeavour to make the data collected suitable for those purposes. Below is a categorization of different types of health statistics, each of which have different uses; a consideration of these categories might provide the basis for discussion:

(a) Demographic and vital

(b) Morbidity and disability

(c) Health service activity

(d) Facilities and resources

(e) Health personnel

(f) Medical alert

(Engel, 1968)

(ii) Any statistics collected must relate to populations at risk-at the simplest level this involves no more than recording separately data from visitors and residents. A further step might be to differentiate the patient contactability element from the statistical address element. For the former a telephone number, a business address, or that of a close friend, might actually be more appropriate than the patient's home. For statistical purposes it is not a precise address but an area for which the population structure is known that is important. While it must be accepted that the information obtained will not always be accurate, no longer requiring a routine address should reduce the amount of deliberately false information, and ensure that the information collected is appropriate to the purpose for which it is required.

(iii) A distinction must be made between problem and diagnosis. The implications of asymptomatic infection detected during a screening process are clearly different from those of an infection causing symptoms severe enough to require hospitalization; and there are many intermediate situations between those extremes. Furthermore, the laboratory diagnosis may be positively misleading - for example a symptomless patient attending because of a definite history of contact with syphilis in whom the only laboratory finding is Candida albicans. Figures for the number of gonorrhoea and syphilis contacts attending are already collected by the D.H.S.S. (Part G of the quarterly return) but not in a form which would allow them to be incorporated into the main body of case statistics: a problem coding used in conjunction with the diagnostic coding would provide a much better record of what is actually happening. 
(iv) Attendances are more appropriate than diagnoses as a measure of workload, but as recorded at present do not distinguish an attendance with a new and complex problem from a brief visit to confirm a negative blood result. The existing system of recording attendance information can be easily modified by using a numerical indication of the type of visit instead of merely recording the fact of a visit.

(v) Precise information must be published on what criteria are required for any particular diagnosis to be made, and under what circumstances relapses or re-infections should be categorized as a new diagnosis. Although the criteria used should be as generally acceptable as possible, it matters less that they should be believed to represent the 'truth' than that they be recognized as providing the uniformity needed for comparisons to be made.

(vi) Distinction must be made between diagnoses, spells of infection, and persons involved. Counting and reporting all three individually would involve more work and would not provide any indication of the relationship between them. A much simpler method, and one with the added advantage of incorporating a failsafe for identification of missed defaulters, is to delay statistical diagnosing for 3 months from the initial visit. Very little extra work would be involved since the getting out and refiling of records would merely take place for the patients who had attended 3 months previously instead of currently, and persons, spells, and diagnoses could be recorded and linked at one and the same time. If the consequent delay in getting the traditional annual statistics were considered important, it would be possible to use October to September figures which would be available at the same time as the present January to December ones.

\section{Conclusions}

In a paper of this kind, intended only to give pause for thought and to provoke discussion, conclusions are neither appropriate nor possible.

Instead a question-'How useful are our present statistics?' Readers unconvinced by the foregoing may like to answer that question themselves by considering the statistics available in relation to the following quotation from one of the world's experts in health statistical methodology.

'Briefly stated, the usefulness of morbidity statistics lies, in general, in their giving information on the following:

(a) How many people suffer from particular diseases, how often, and for how long;

(b) What demands these diseases place on the medical and public health resources; and what financial loss they cause;

(c) How fatal the different diseases are;

(d) To what extent people are prevented by these diseases from carrying on their normal activities;

(e) To what extent diseases are concentrated in particular groups of the population, e.g. according to age, ethnic group, occupation, or place of residence;

( $f$ ) How far the above factors vary from time to time (variation according to season or from year to year).

(g) What is the effect of medical care and health services on the control of disease incidence.'

(Swaroop, 1960.)

\section{Summary}

Various aspects of the British statistics relating to sexually-transmitted diseases are examined. Defects in these are illustrated by data from a series of surveys. It is suggested that the information being collected and published is incomplete by an unknown amount, inadequate because it tells only of laboratory diagnoses, and unusable at a local level because it relates to no identifiable population.

Some suggestions are made as to how the data collected might be made more useful: the first and most important is that a working party should decide for what purposes the statistics are required.

\section{References}

BebBington, R. (1969) f. roy. Coll. gen. Practit., 18, 27

Beeton, D. G. (1969) Practitioner, 202, 830

British Co-operative Clinical Group (1959) Brit. f. vener. Dis., 35, 111

(1968) Ibid., 44, 299 (Annex II)

Catterall, R. D. (1973) Ibid., 49, 126

and Morton, R. S. (1970) Brit. med. F., 3, 699

Engel, A. (1968) 'Perspectives in Health Planning'. Athlone Press, London

HeYwOOD, C. P., and BACON, P. M. (1973) Brit. f. vener. Dis., 49, 540

LogAN, W. P. D., and Cushion, A. A. (1958) 'Morbidity Statistics from General Practice', vol. 1, Studies on Medical and Population Subjects', No. 14. General Register Office, London

MCGREGOR, R. M. (1969) 'The Work of a Family Doctor'. Livingstone, Edinburgh

MAHONEY, J. D. H. (1972) Brit. F. vener. Dis., 48, 71

Pemberton, J., McCann, J. S., Mahoney, J. D. H., MackenzIE, G., Dougan, H., and HaY, I. (1972) Ibid., 48, 391

SwarOop, S. (1960) 'Introduction to Health Statistics'. Livingstone, Edinburgh

ThOMPSON, B., and RUTHERFORD, H. W. (1972) Brit. F. vener. Dis., 48, 209

WIGFIRLD, A. S. (1971) Brit. med. F., 4, 342 